\title{
PROJECT EVALUATION IN LOCAL GOVERNMENTS TO REALIZE WOMEN ACTIVE PROMOTION SOCIETY IN JAPAN
}

\begin{abstract}
These days, in Japan, it is required for women to participate and advance in the workplace because of labor population decline. However, it is very difficult for them to do that because of the Japanese history such as the patriarchal system. The Basic Act on gender-equal society established in 1999 and various projects for women to participate in the society began in local governments. On the other hand, in 1990s project evaluation was introduced to local government administration to boost the efficiency of projects. By the way, because any project belongs to a program, project evaluation has to be related to outcome of the program. However, project evaluation often is independent on the program. The purpose of this study is to propose a framework of project evaluation to realize a society promoting women's participation and advance in the workplace in Japan. This method calculates Contribution degree of projects with respect to the program with the AHP/ANP in order to link project evaluation to the program. In this study we evaluated the case of Chino city in Japan, but this framework is possible to apply to projects of the program about gender equality in other local governments.
\end{abstract}

Keywords: local government, gender equality, project evaluation, contribution degree.

\section{Introduction}

These days, the labor population is decreasing in Japan, so women's participation and advance in the workplace is required. However, it is very difficult for them to work outside because of Japanese history such as the patriarchal system. To solve this issue, Japanese legislation has progressed. For example, the Basic Act on gender-equal society established in 1999 and local governments have made the program about gender equality. Local government administration activities are of policies, programs and projects. The project is a concrete activity, which belongs to a program.

In 1990s project evaluation was introduced to Japanese local government administration to boost the efficiency of projects. However, it seemed unfunctional because the project evaluation was not often linked to the program. The purpose of this study is to show a framework of project evaluation linked to the program about gender equality in Japan. This method calculates Contribution degrees of projects with respect to the program with the AHP. This links project evaluation to the program. In this study we evaluated the case of Chino city in Japan, but this framework is possible to apply to the projects about gender equality in other Japanese local governments.

\section{Literature Review}

There are a lot of literatures about women's social advancement by Japanese researchers. Naito, who is a famous researcher of Japanese gender equality issue, classified the viewpoints of the Japanese gender equality policy into the following three (Naito, 2015): the division of labor by gender, the wage gap by gender and job 
promotion gap by gender. We used these viewpoints as criteria in the hierarchy. Kegasawa showed some functions promoting a society about gender equality (Kegasawa, 2015). This result was also used in the hierarchy.

Naito, K. (2015). Gender equality society formation policy. In Naito, K. \& Yamaya, K. (Eds.). Gender equality policy (pp.1-12). Japan: Koyo Shobo.

Kegasawa, Y. (2015). Consultation business in the gender equality center. In Naito, K. \& Yamaya, K. (Eds.). Gender equality policy (pp.53-70). Japan: Koyo Shobo.

\section{Hypotheses/Objectives}

There are policies, programs and projects in administration activities. Any project belongs to a program. So project evaluation must be linked to outcome of the program. However, it is difficult to evaluate the contribution degree of the project to the program. One of the purpose of this study is to construct a framework of project evaluation of the projects linked to the program of gender equality in a local government in accordance with the framework of project evaluation proposed by Iida (Iida, 2018). The other is to show the calculational procedure of the method by a realistic example.

\section{Research Design/Methodology}

In this section we constructed the hierarchy, which is a framework of project evaluation linked the program to realize women active promotion society in Japan. This can be used in other local governments. The procedure in this section is the same as the AHP

First, Level 1 of the hierarchy is the goal of the program "The program of realizing a society promoting women's participation and advance in the workplace", to which these projects belong. Next, Level 2 is of viewpoints of the program. In this case these are of three viewpoints V1, V2 and V3 by Naito (Naito, 2015) as follows:

- V1 the division of labor by gender: Viewpoint that women are often domestic labor at home, while men work outside.

- V2 the wage gap by gender: Viewpoint that women's wage is often lower than men's one.

- V3 job promotion gap by gender: Viewpoint that women are often excluded from decision making and tend to be subordinate.

Finally, Level 3 is of functions of activities to solve the issues from the viewpoints of the program. In this case these are of six functions F1, F2,.., F6 according to results by Kegasawa (Kegasawa, 2015) as follows:

- F1 Place for advice: Function of consultation such as telephone and individual consultation.

- F2 Opportunity of learning: Function of learning issues of gender equality such as courses and workshops.

- F3 Environment for access to information: Function of offering information to solve issues related to gender equality such as library and website.

- F4 Interaction with specialists: Function of connecting to experts like psychological counselors and attorneys to solve issues related to gender equality such as a party after a lecture.

- F5 Grasp of current situation: Function of surveying the current situation such as questionnaire survey and consciousness investigation.

- F6 Support of promotion in the workplace: Function of supporting of promotion of women's participation in decisions in the workspace such as certifications for companies promoting women's participation and advance in the workplace. 
Thus we have the following hierarchy:

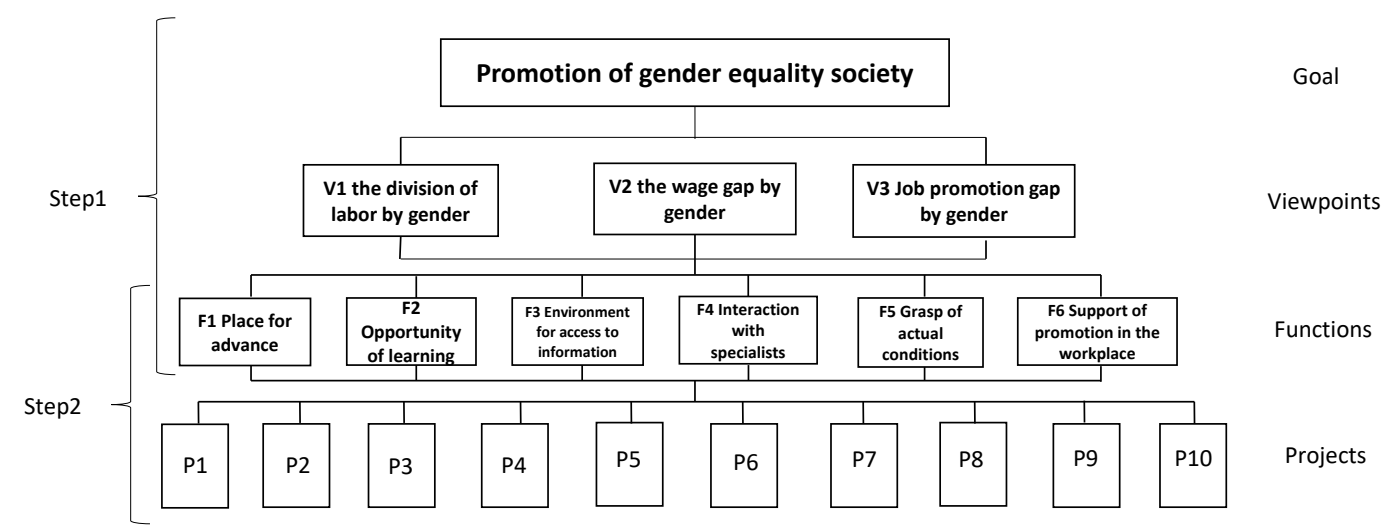

Figure1 Hierarchy for calculating contribution degree

By the way, as mentioned above, we used the case of Chino city here. This city had ten projects for this program in 2017 as follows:

- P1 Held gender equality promotion competition

- P2 Employment promotion project for gender equality

- P3 Gender equality project in subregion

- P4 Expansion of promotion of female committee members

- P5 Work life balance promotion support project

- P6 Guidelines for district self-governing association creation project

- P7 Promotion of certification business

- P8 Gender equality promotion project for home and education

- P9 Welfare 21 Venus plan promotion project

- P10 Formulation of the 3rd Chino-city gender equality plan.

As shown in Figure 1, these projects are placed on the bottom level of the hierarchy. This four-layer hierarchy is the framework of project evaluation about gender equality, based on (Iida, 2018). In the next section we calculated weights of items, contribution degree of each project and relative evaluation values of projects.

\section{Data/Model Analysis}

We calculated weights of items in the hierarchy (Figure 1) with paired comparisons of the AHP.

(1) Weights of four viewpoints with respect to the program

We used Question: which is more important for realizing a society promoting women's participation and advance in the workplace? And how much? We had Table 1.

Table 1

Comparison table of viewpoints with respect to Goal and the weights

\begin{tabular}{ccccc} 
Program & V1 & V2 & V3 & Weights \\
\hline V1 & 1 & 5 & 3 & 0.701 \\
V2 & $1 / 5$ & 1 & 3 & 0.202 \\
V3 & $1 / 5$ & $1 / 3$ & 1 & 0.097 \\
\hline & & & C.I. $=$ & 0.068
\end{tabular}

(2) Weights of six functions with respect to each viewpoint 
ISAHP Article: A Style Guide for Paper Proposals To Be Submitted to the International Symposium on the Analytic Hierarchy Process 2018, Hong Kong, HK.

We used Question: which is more important (as functions of activities) to solve the issues from the viewpoint? And how much? We had Table 2.

Table 2

Evaluation table of functions with respect to each viewpoints

\begin{tabular}{cccc} 
& V1 & V2 & V3 \\
\hline F1 & 0.260 & 0.073 & 0.028 \\
F2 & 0.163 & 0.416 & 0.356 \\
F3 & 0.380 & 0.268 & 0.098 \\
F4 & 0.064 & 0.036 & 0.030 \\
F5 & 0.039 & 0.041 & 0.105 \\
F6 & 0.094 & 0.167 & 0.382 \\
\hline C.I. & 0.087 & 0.090 & 0.075
\end{tabular}

(3) Synthesizing evaluation of functions with respect to the program

We combined values in Table 1 and those in Table 2 and obtained Table 3 like the AHP.

Table 3

Synthesizing evaluation values of functions

\begin{tabular}{l|cccccc|c} 
Function & F1 & F2 & F3 & F4 & F5 & F6 & Sum \\
\hline Synthesizing evaluation & 0.200 & 0.233 & 0.330 & 0.055 & 0.046 & 0.137 & 1.000
\end{tabular}

(4) Weights of projects with respect to functions We remark all the projects do not have all the functions. So, we compared only projects with meaningful function by paired comparison of the AHP and obtained Table 4 .

Table 4 Weights of projects with respect to meaningful functions

\begin{tabular}{ccccccc} 
& F1 & F2 & F3 & F4 & F5 & F6 \\
\hline P1 & 0.875 & 0.167 & 0.311 & 0.750 & & \\
P2 & & & 0.054 & & 0.571 & \\
P3 & & & & & 0.257 & 0.143 \\
P4 & & & & & 0.110 & 0.714 \\
P5 & & & 0.059 & & & \\
P6 & & & & & & 0.143 \\
P7 & & & 0.150 & & & \\
P8 & & 0.833 & 0.287 & 0.250 & & \\
P9 & 0.125 & & 0.112 & & & \\
P10 & & & 0.027 & & 0.062 & \\
\hline Sum & 1.000 & 1.000 & 1.000 & 1.000 & 1.000 & 1.000 \\
\hline C.I. & 0.000 & 0.000 & 0.077 & 0.000 & 0.079 & 0.000
\end{tabular}

(5) Contribution degrees of project to the program

Here we calculated contribution degree of each project to the program. We combined Table 3 and Table 4 to obtain Table 5.

Table5

Contribution degrees of projects for the program

\begin{tabular}{l|cccccccccc|c} 
Project & P1 & P2 & P3 & P4 & P5 & P6 & P7 & P8 & P9 & P10 & Sum \\
\hline Contribution degree & 0.357 & 0.044 & 0.031 & 0.103 & 0.020 & 0.020 & 0.050 & 0.302 & 0.062 & 0.012 & 1.000
\end{tabular}


(6) Relative evaluation values of projects with respect to the program

Finally, we calculated relative evaluation values of projects with respect to the program by the following formula: Relative evaluation value of a project $=$ contribution degree $\times$ individual evaluation value of itself (see (Iida, 2018)). In this study we used the target achievement rate of each project in Chino's report (Chino city, 2017) as an individual evaluation value. In the case that a project has several targets, we used the average of their achievement rates.

Table 6

Relative evaluation values of projects with respect to the program

\begin{tabular}{l|cccccccccc} 
Project & P1 & P2 & P3 & P4 & P5 & P6 & P7 & P8 & P9 & P10 \\
\hline Contribution degree & 0.357 & 0.044 & 0.031 & 0.103 & 0.020 & 0.020 & 0.050 & 0.302 & 0.062 & 0.012 \\
Target achievement rate (\%) & 87.5 & 140.0 & 77.1 & 90.0 & 40.0 & 55.0 & 45.0 & 40.0 & 50.0 & 100.0 \\
Relative evaluation & 31.24 & 6.16 & 2.40 & 9.27 & 0.8 & 1.1 & 2.25 & 12.08 & 3.10 & 1.20
\end{tabular}

\section{Limitations}

We calculated Contribution degree of each project by the AHP. This means that all the items of a hierarchy were supposed to be independent on each other. We have better take dependence of items into account. In this study one of authors, who is an officer in Chino, evaluated weights of all the items to show a realistic example, although he studied many kinds of documents and websites about gender equality in Chino. It is suitable that synthesizing evaluation values of functions (Table 3) should be obtained by committee members related to the destination of the community in Chino city. On the other hand, weights of projects with respect to functions (Table 4) should be obtained by representatives of all the projects, because they understand projects well.

\section{Conclusions}

In this study, we showed the framework of evaluation of projects in local government to the program about gender equality by deciding viewpoints and functions in the hierarchy. This framework may be able to measure how much the local government is mature in gender equality. We need to polish this framework up more in the future.

\section{Key References}

Chino city. (2017). Project evaluation sheets of the program: gender equality. No. 0605-01-01 to 10.

Iida, Y. (2018). A framework of project evaluation based on outcome in local government. The proceedings in ISAHP2018.

Saaty, T.L. (2010). Principia Mathematica Decernendi-Mathematical Principles of Decision Making. Pittsburgh, PA: RWS Publications. 